\title{
Erratum: Analysis of cyprodinil in leek and pepper and its decline under field conditions
}

\author{
Congyun Liu • Suli Wang • Li Li • Huiyu Zhao • \\ Shuren Jiang · Fengmao Liu
}

Published online: 29 December 2010

(C) Springer Science+Business Media B.V. 2010

\section{Erratum to: Environ Monit Assess DOI 10.1007/s10661-010-1730-y}

The original version of this article unfortunately contained errors.

Page 3: In the part of "sampling and storage", second paragraph, "To investigate the terminal

The online version of the original article can be found at: http://dx.doi.org/10.1007/s10661-010-1730-y of the article with published errors.

C. Liu $\cdot$ H. Zhao $\cdot$ S. Jiang $\cdot$ F. Liu ( $\bowtie)$

College of Science, China Agricultural University, Beijing, 100193, People's Republic of China e-mail: liufengmao@yahoo.com

S. Wang

Heibei North University, Zhangjiakou, 075000, People's Republic of China

\section{Li}

State Key Laboratory of Integrated Management of Pest Insects and Rodents, Institute of Zoology, Chinese Academy of Sciences, Beijing, 100101, People's Republic of China residue in leek, pepper, and soil, the samples were collected at a preharvest interval of 7 and 14 days from each plot." should be corrected to "To investigate the terminal residue in leek, pepper, and soil, the samples were collected at a preharvest interval of $\mathbf{1 4}$ days from each plot."

Page 5: In the part of "The terminal residue of cyprodinil in leek, pepper, and soil", "the terminal residue of cyprodinil in leeks ranged from 0.33 to $5.39 \mathrm{mg} / \mathrm{kg}$ in Beijing and from 1.04 to $14.37 \mathrm{mg} / \mathrm{kg}$ in Shandong 7 and 14 days after pesticide application." should be corrected to "the terminal residue of cyprodinil in leeks ranged from 0.33 to $\mathbf{0 . 3 7} \mathbf{~ m g / k g}$ in Beijing and from 1.04 to $4.86 \mathrm{mg} / \mathrm{kg}$ in Shandong 14 days after pesticide application."

In the next paragraph, "The terminal residues of cyprodinil in pepper were between ND (no pesticide residue was detected) and $2.06 \mathrm{mg} / \mathrm{kg}$ in Beijing, Anhui and Shandong 7 and 14 days after pesticide application. The terminal residues of cyprodinil in soil ranged from ND to $13.67 \mathrm{mg} / \mathrm{kg}$." should be corrected to "The terminal residues of cyprodinil in pepper were between ND (no pesticide residue was detected) and $0.97 \mathbf{~ m g} / \mathbf{k g}$ in Beijing, Anhui and Shandong 14 days after pesticide application. The terminal residues of cyprodinil in soil ranged from ND to $\mathbf{2 . 4 5} \mathbf{~ m g / k g . " ~}$ 